Ana Paula Neves Lopes ${ }^{1}$

Viviane Marcowicz Burgardt²

resumo

$\bigcirc$ presente artigo trata do perfil dos sujeitos idosos que buscam, através da Educação de Jovens e Adultos (EJA), uma maneira de reinserção ao mercado de trabalho. Procura-se contextualizar o apoio e amparo das Leis, Decretos e Estatutos para com esses idosos, priorizando seus direitos adquiridos e reduzindo os embates construídos pelo sistema capitalista que não atende às especificidades e aos anseios desses. Dessa forma, este artigo mostra o distanciamento das políticas públicas educacionais para o atendimento desses sujeitos. O objetivo principal é discutir acerca das consequências e formas de como a sociedade prevê a educação e o trabalho para esses idosos. Nota-se também a importância do uso das novas tecnologias por esses idosos na interação com as outras gerações e ainda pauta-se a educação gerontológica como uma forma mais adequada para atender aos anseios e necessidades dessa parcela da população. A partir de todos esses aspectos pretende-se demonstrar que o idoso é um cidadão ativo e participante, que possui a mesma importância que os demais membros da sociedade. A metodologia de pesquisa para esse referido artigo respalda-se na união do estudo de caso do tipo etnográfico com a pesquisa de levantamento, de cunho qualitativo, numa abordagem exploratória. $\bigcirc$ texto desse estudo de pesquisa é de extrema relevância, principalmente aos docentes da EJA e demais educadores, visto que necessitam ampliar sua formação nessa área do conhecimento.

1 Licenciada em Pedagogia pela Universidade Estadual de Ponta Grossa (UEPG). Pós-graduada em Educação Especial e Inclusão Educacional pela Universidade Estadual de Ponta Grossa (UEPG). Especialista em Educação Profissional Integrada à Educação Básica na Modalidade Educação de Jovens e Adultos pela Universidade Tecnológica Federal do Paraná (UTFPR). Pedagoga no Ensino Fundamental e Médio - regular e EJA, pela Secretaria de Estado da Educação do Paraná / Núcleo Regional de Ponta Grossa (SEED- PR/ NRE-PG).E-mail: anapaulanlopes@hotmail.com

2 Licenciada em Pedagogia pela Universidade Estadual de Ponta Grossa (UEPG). Pós-graduada em Gestão Escolar: Supervisão e Orientação pelo Instituto de Estudos Avançados e Pós-Graduação (ESAP). Especialista em Educação Profissional Integrada à Educação Básica na Modalidade Educação de Jovens e Adultos pela Universidade Tecnológica Federal do Paraná (UTFPR). Professora no Ensino Fundamental pela Secretaria Municipal de Educação de Ponta Grossa (SME- PG). E-mail: vimarbur@ hotmail.com 
As transformações mercadológicas advindas do capitalismo e das leis de oferta e procura acentuam a desqualificação profissional de uma parcela da população, gerando, entre outras consequências, a falta de emprego e a instabilidade no mesmo, impulsionando, dessa forma, a concorrência e a competitividade.

A Educação de Jovens e Adultos (EJA) surge como uma medida paliativa no atendimento dessa população que retorna à escola com vistas ao mercado de trabalho. No entanto, um novo perfil de alunos adentra a essa modalidade de ensino básico, entre eles, temos o idoso.

O Estatuto do Idoso apresenta alguns direitos que esse indivíduo tem a partir da Lei n⿳ํㅜ 10741 de 01/10/2003, que dispõe e dá algumas providências.

Em seu primeiro artigo deixa claro que idoso é a pessoa com idade igual ou superior a 60 (sessenta) anos. Entre outros artigos dessa lei, também está previsto que não é apenas obrigação dos familiares assistirem o idoso, mas sim da sociedade em geral (pessoas físicas e jurídicas), além do poder público (Poderes Executivo, Legislativo e Judiciário).

Também se compreende como prioridade:

I - atendimento preferencial imediato e individualizado junto aos órgãos públicos e privados prestadores de serviços à população;

॥ - preferência na formulação e na execução de políticas sociais públicas específicas;

III - destinação privilegiada de recursos públicos nas áreas relacionadas com a proteção ao idoso;

N - viabilização de formas alternativas de participação, ocupação e convívio do idoso com as demais gerações;

V - priorização do atendimento do idoso por sua própria família, em detrimento do atendimento asilar, exceto dos que não a possuam ou careçam de condições de manutenção da própria sobrevivência;

VI - capacitação e reciclagem dos recursos humanos nas áreas de geriatria e gerontologia e na prestação de serviços aos idosos;

VII - estabelecimento de mecanismos que favoreçam a divulgação de informações de caráter educativo sobre os aspectos biopsicossociais de envelhecimento;

VIII- garantia de acesso à rede de serviços de saúde e assistência social local. (BRASIL, 2003, p. 8). 
Nos artigos $4^{\circ}, 5^{\circ}$ e $6^{\circ}$ temos a punição na forma da lei para qualquer ato de negligência, discriminação, violência, crueldade, opressão, atentado e violação dos direitos, e ameaça, sendo dever de todos coibirem essas ações.

O crescimento da população idosa é uma constante em nosso país, e pode ser considerado um fator negativo em torno do mercado de trabalho, pois a inclusão dos idosos no mesmo torna-se apenas um cumprimento legal e não valoriza seu conhecimento e sua experiência. Assim, segundo pesquisas do Instituto Brasileiro de Geografia e Estatística (IBGE),

\begin{abstract}
Em vários países, as populações estão envelhecendo. Estudos mostram que o número de pessoas idosas cresce em ritmo maior do que o número de pessoas que nascem acarretando um conjunto de situações que modificam a estrutura de gastos dos países em uma série de áreas importantes. No Brasil, o ritmo de crescimento da população idosa tem sido sistemático e consistente. Segundo a Pesquisa Nacional por Amostra de Domicílios - PNAD 2009, o País contava com uma população de cerca de 21 milhões de pessoas de 60 anos ou mais de idade. Com uma taxa de fecundidade abaixo do nível de reposição populacional, combinada ainda com outros fatores, tais como os avanços da tecnologia, [...], atualmente o grupo de idosos ocupa um espaço significativo na sociedade brasileira. No período de 1999 a 2009, o peso relativo dos idosos (60 anos ou mais de idade) no conjunto da população passou de 9,1\% para 11,3\% (BRASIL, 2010, p. 191).
\end{abstract}

Com o aumento da população idosa, tem-se uma elevação dos gastos públicos com relação à saúde, previdência e outros; segundo Patrocínio (2008, p. 204)

[...] os trabalhadores que contribuíram 35 anos com o INSS e as trabalhadoras que contribuíram 30 anos possuem direito à aposentadoria [...] Contudo, muitas vezes, os cidadãos não conseguem adquirir esse direito e continuam no mercado de trabalho.

A qualidade e as condições ofertadas nem sempre levam em conta as especificidades desses indivíduos. Com isso, inicia-se o regresso aos bancos escolares com objetivo de adentrar novamente ao mundo e ao mercado de trabalho, pois é significativa uma ocupação e a participação na sociedade, visto, também, que necessitam suprir suas necessidades.

Nesse aspecto, voltado ao perfil do trabalhador e sua recolocação profissional, alguns apontamentos apresentam distorções no cenário brasileiro (PATROCÍNIO, 2008, p. 206).

O trabalho ofertado volta-se aos sujeitos que, em outra época, tiveram uma educação mais aprimorada. Muitas vezes, falam outro idioma, possuem 
experiências e habilidades. Dessa forma, trabalhadores que não tiveram acesso à educação ficaram excluídos do mercado de trabalho formal, o que resulta na desigualdade de oferta de empregos, voltados à informalidade/ subempregos, baixa qualidade de educação e vida.

Como previsto no Estatuto do Idoso (2003), é obrigação do Estado a garantia da preservação da saúde, da liberdade, do direito à vida, do respeito, da dignidade, da previdência e assistência social, da habitação, do transporte, da educação e do trabalho.

Sobre esses dois últimos aspectos que trataremos com mais profundidade, guiando-nos pela experiência na EJA, temos a particular preocupação voltada ao atendimento dos idosos quanto ao currículo, às metodologias, à experiência profissional do educador, ao material didático adequado para esse público e à utilização das tecnologias. Também o respeito às condições intelectuais, psicológicas e físicas desses sujeitos, levando em conta o interesse de voltar para a escola e participar da educação formal ${ }^{3}$ na EJA, de modo a proporcionar o regresso ao mercado de trabalho.

Diante desses aspectos, surgem algumas inquietações: $\mathrm{O}$ processo de educação de jovens e adultos contempla 'adultos' com idade superior a 60 (sessenta) anos, ou seja, idosos, ou existe uma educação específica para esses?

Há uma preparação dos profissionais da educação para atender a essa demanda?

Os idosos estão preparados para serem inseridos novamente no mercado de trabalho? O que garante o acesso dos idosos no mercado de trabalho?

\section{Um olhar sobre o campo de estudo}

O campo de pesquisa delineou-se em uma instituição da rede estadual de ensino, na modalidade de EJA de nível fundamental II e Ensino Médio, e contou com um diferencial em uma das turmas de nível fundamental II (5 $5^{\text {a }}$ à $8^{\underline{a}}$ séries, atuais $6^{0}$ à $9^{o}$ anos) - turno noturno, turma coletiva e mista -, com matrículas e frequências de um número expressivo de idosos (ambos os sexos), que participavam das aulas presenciais ativamente com indivíduos de outras faixas etárias (a partir de 15 anos).

\footnotetext{
3 Segundo GADOTII (2005, p. 2): A educação formal tem objetivos claros e específicos e é representada principalmente pelas escolas e universidades. A educação não formal é mais difusa, menos hierárquica e menos burocrática. Os programas de educação não formal não precisam necessariamente seguir um sistema seqüencial e hierárquico de "progressão". Podem ter duração variável, e podem, ou não, conceder certificados de aprendizagem.
} 
Esse grupo de idosos frequentava três disciplinas distintas com datas determinadas para início e término das mesmas, contemplando o segundo semestre letivo, o qual demarca o período compreendido para a coleta de dados.

A base metodológica para essa pesquisa respalda-se na união de métodos, ou seja, é multimetodológica. Nesse sentido, utiliza-se do estudo de caso do tipo etnográfico e da pesquisa de levantamento, apenas para a classificação da amostragem representativa.

Assim, segundo critério de amostragem estabelecido por Bickman e Rog (1998), a pesquisa de levantamento, ou survey, deu-se por cotas, enaltecendo a população idosa com a utilização de variáveis nominais como idade, objetivos do retorno escolar e a composição minoritária de indivíduos idosos na EJA, compondo um subgrupo específico de determinada instituição educacional na cidade de Ponta Grossa-PR.

A análise final dos dados baseia-se na pesquisa qualitativa, pois, segundo Chizzotti (2006, p. 28), o termo qualitativo "implica uma partilha densa com pessoas, fatos e locais que constituem objetos de pesquisa, para extrair desse convívio os significados visíveis e latentes que somente são perceptíveis a uma atenção sensível".

O enfoque sob o método de pesquisa estudo de caso etnográfico, de cunho exploratório, permite subsidiar e dar prosseguimento à mesma, guiando-se pela experiência e atuação profissional na EJA. Assim, pode-se observar o tema/ objeto com aproximação, pois é no ambiente natural que o investigador frequenta e participa do local de estudo, compreendendo a importância do contexto na vida dos sujeitos analisados.

Para André (2008, p. 41),

\section{A pesquisa do tipo etnográfico, que se caracteriza fundamentalmente por um contato direto do pesquisador com a situação pesquisada, permite reconstruir os processos e relações que configuram a experiência escolar diária. \\ Por meio de técnicas etnográficas de observação participante e de entrevistas [...], é possível documentar o não-documentado, isto é, desvelar os encontros e desencontros que permeiam o dia-a-dia da prática escolar [...].}

Dessa forma, na medida em que os problemas conduziam a questionamentos, delineou-se a melhor maneira de coletar os dados, pois o contato com o ambiente e os sujeitos possibilitou a observação direta participante não estruturada, bem como o diálogo com os demais docentes que também atuavam diretamente com o grupo de idosos. Assim, contribuíram positiva- 
mente através de entrevistas semiestruturadas e relatos informais sob a perspectiva de educação e trabalho para com esses, norteando o estudo de caso.

Além disso, os depoimentos e relatos cotidianos dos indivíduos envolvidos no processo de ensino apontavam a imprevisibilidade que demarca este tipo de pesquisa e as devidas reformulações necessárias para o entendimento dessa realidade. "As decisões sobre como analisar e apresentar os dados também não podem ser predeterminadas, a não ser em linhas bem gerais. É com base na forma como a pesquisa vai se desenvolvendo e em decorrência dela que essas decisões vão ficando mais claras" (ANDRÉ, 2008, p. 60).

Dessa forma, a flexibilidade, as percepções e a sensibilidade das pesquisadoras sobre seu objeto de estudo fizeram-se presentes a todo o momento. As incertezas e dúvidas tornam-se úteis na redefinição e reflexão sobre o que e para que se pretende analisar determinado grupo e contexto social. Também, reporta-se à viabilidade dessa pesquisa no que tange aos indicativos reais da prática existente com o confrontamento idealista documental, baseado em leis, estatutos, etc. Com isso, reconhece-se a credibilidade da mesma, ao especificar o campo de atuação, os métodos e os instrumentos utilizados para a coleta de dados.

No esquema de triangulação da pesquisa, a ética, o compromisso e a fidedignidade respaldaram-se na atuação e confirmação de outros profissionais docentes da instituição, bem como da análise documental e interpretação dos dados coletados. Além disso, os objetivos da pesquisa ficaram explícitos para os sujeitos envolvidos no entorno escolar, com isso o cronograma de atendimento a esses se adequou para subsidiar respostas às indagações, questionamentos e demais curiosidades elencadas.

Nesse sentido, elencou-se algumas alternativas externas para sanar o currículo educacional da EJA. Assim, através de palestras, encontros, aulaspasseio e outros, pode-se realmente demonstrar a união da teoria escolar com a prática diária de vida, enaltecendo o verdadeiro sentido educacional.

Para Minayo (2001, p. 17), "nada pode ser intelectualmente um problema se não tiver sido, em primeiro lugar, um problema da vida prática", ou seja, a pesquisa necessita estar veiculada à realidade, buscando respostas, possibilitando modificações no modo de pensar da sociedade quanto aos preconceitos e exclusões que permeiam a vida social.

Assim, a pesquisa para ser satisfatória, necessita relacionar-se com a vida real; Minayo (1994, p. 23) refere-se à pesquisa como "uma atitude e uma prática teórica de constante busca que define um processo intrinsecamente inacabado e permanente", explicitando, dessa forma, a constante busca por reflexões que guiem a prática educacional e a evolução social. 
Dessa maneira, busca-se com essa pesquisa auxiliar a prática docente dos profissionais da educação. Além de desmistificar questionamentos pautados pela falta de conhecimento, que relacionam os idosos na EJA e no mercado de trabalho.

A partir da observação realizada no campo educacional da EJA, nota-se que os idosos são minoria nessa modalidade de ensino, porém o comportamento desses alunos tem-se modificado, acompanhando as transformações da sociedade. Por outro lado, a educação para esses sujeitos ainda não se encontra organizada em seu entorno curricular, com políticas públicas específicas, programas governamentais de atendimento educacional para esse grupo etário, ou, ainda, formação de professores especialistas na área de gerontologia.

Entende-se por gerontologia:

campo multi e interdisciplinar que visa à descrição e à explicação das mudanças
típicas do processo do envelhecimento e de seus determinantes genético-
biológicos, psicológicos e socioculturais. Interessa-se também pelo estudo das
características dos idosos, bem como pelas várias experiências de velhice e
envelhecimento ocorridas em diferentes contextos socioculturais e históricos
(MADDOX, 1987 apud NERI, 2008, p. 95).

Martín García 41994 (apud OSORIO, 2003, p. 281) diferencia termos gerontológicos ligados à ação educativa,

ao reelaborar a categorização de proposta [...] destaca, em primeiro lugar, uma
distinção entre <gerontologia educativa> e <educação gerontológica>, sobre a
qual não existe um consenso generalizado nem definitivo. O primeiro termo faz
referência à aprendizagem das pessoas seniores, interessando-se por todos
os aspectos educativos que se relacionam com o processo, os mecanismos,
os tipos e as estratégias de aprendizagem desse grupo. O segundo prende-se
mais com a sociedade, o ensino e a profissionalização nesse campo.

Assim, a gerontologia educativa compreende os métodos, as técnicas do processo decorrente da aprendizagem dos idosos, levando em conta as necessidades dos mesmos e indo ao encontro da metodologia adequada para essa

4 MARTíN GARCÍA, Antonio V. Educación y Envejecimiento. Barcelona: PPU, 1994. Apud OSÓRIO, 2003 . 
faixa etária. Já a educação gerontológica é o processo centrado na formação de profissionais para o trabalho com os idosos, pautado nas considerações programadas por ações governamentais, ou de políticas públicas.

Nota-se que a educação anterior desses idosos era a preparação para o trabalho; dessa forma, a educação primordial era feita com base na alfabetização, com o intuito de formar mão-de-obra e preencher a demanda do mercado de trabalho. Contudo, Vargas (2010) nos diz que a educação para os idosos pode ocorrer de maneira informal, em diversos contextos da vida social. Remete-se ainda à construção de conhecimentos e habilidades a partir do manuseio e da utilização de equipamentos eletrônicos e tecnológicos.

A educação do idoso deve privilegiar as suas necessidades específicas, com intuito de sua inserção na sociedade, tornando-se um membro participativo da mesma. "[...] um processo global e integrado, de formação técnica e profissional do adulto - e sua forma inicial - feito em função da vida e das necessidades do trabalho; um processo educativo diversificado" (BEISIEGEL, 1974, p. 83, apud SOUZA, 2002). Assim, o idoso poderá optar pela educação formal na EJA, ou por espaços alternativos de educação informal que, segundo Vargas (2010), pode ocorrer através da participação em eventos culturais, passeios, viagens, etc. Dessa forma, há uma troca de experiências com pessoas de diferentes faixas etárias que favoreceria a interação social e a aquisição de novos conhecimentos, antes pouco utilizados, como, por exemplo: as novas tecnologias.

O contato com essas novas tecnologias e a troca de experiências com outras gerações é de fundamental importância socializadora, visto que ainda existem preconceitos, dificuldades em usufruir dessas tecnologias (tanto pelo poder aquisitivo de algumas, quanto pelo manuseio). Também referente ao campo educacional, vê-se que se estabelece um processo de seleção, competição e desqualificação sobre quem está apto ou não (apto) para utilizar dessas novas tecnologias na prática e incorporá-las à vida moderna.

Contudo, o Estatuto do Idoso prevê, em seu artigo 21, que o Poder Público garantirá o acesso do idoso na educação formal, “... adequando currículos, metodologias e material didático aos programas educacionais a ele destinados" (BRASIL, 2003, p. 17). Porém, não é esse o contexto observado na prática, pois mesmo havendo programas de inserção desses indivíduos em Instituições de Ensino Universitárias, esses, para adentrarem, já necessitam ter o Ensino Fundamental completo.

Nesse mesmo artigo (21) do Estatuto, temos o parágrafo $1^{\circ}$, que fala: “Os cursos especiais para idosos incluirão conteúdo relativo às técnicas de comunicação, computação e demais avanços tecnológicos, para sua integração à vida moderna" (BRASIL, 2003, p. 17). Ainda, para Cachioni (2008a, p. 93-94) 
No Brasil, existem várias possibilidades de realização de programas relacionados à gerontologia educacional, abrangendo educação não formal, educação formal, atividades visando o lazer e à sociabilidade, reciclagem profissional, mudança de atitudes e apoio psicossocial, dentre outros. No entanto, esse campo expressa-se mais caracteristicamente em programas pertencentes à modalidade de Universidade da Terceira Idade, normalmente funcionando como projetos de extensão.

Esses cursos de caráter extensionista não são direcionados a todos os idosos, restringindo os alunos da EJA, pois eles preveem objetivos diferentes e exigem que já se tenha concluído a Educação Básica para adentrar na Universidade Aberta da Terceira Idade (UNATI) ${ }^{5}$.

Na EJA ocorre um ensino seguindo a divisão: turmas individuais e coletivas para atender o ensino fundamental e médio. Os alunos que adentram nessa modalidade optam por escolher disciplinas de seu interesse imediato, as demais são feitas posteriormente. Assim, os alunos podem concluir o curso em tempos diferentes, pois essa modalidade atende as necessidades, os anseios e as especificidades de cada um.

Nas turmas individuais, o profissional da educação ministra diferentes conteúdos, de acordo com o nível de aprendizagem de cada aluno. Essa divisão da modalidade da EJA é voltada para os alunos que trabalham em turnos. Por isso, são contabilizadas apenas suas presenças, tendo o privilégio de concluir conforme suas possibilidades. Nas turmas coletivas, atende-se a uma classe onde os alunos progridem no mesmo nível, mas cada um com suas dificuldades específicas. No entanto, ela reflete o modelo da classe regular, onde a presença do aluno é importante para o acompanhamento dos conteúdos ministrados.

Dessa forma, o ensino ofertado não é adequado para o idoso e não se levam em consideração suas especificidades. Não há uma formação continuada dos profissionais que atuam nessas instituições, que deveriam se adequar às necessidades dos idosos, buscando metodologias diferenciadas que privilegiem o acesso e o desenvolvimento dos conhecimentos e saberes historicamente construídos e que tenham relevância para a vida dos mesmos.

O idoso procura não só conhecimentos formais, mas também uma valorização pessoal, pois, apesar de sua idade avançada, ainda é um participante ativo da sociedade, com direitos e deveres, como todos os outros cidadãos.

5 Para Cachioni (2008b, p. 209), "são várias as denominações que as instituições de nível superior em todo mundo adotaram para designar o trabalho educacional dirigido ao adulto maduro e ao idoso". Geralmente, elas estão ligadas aos objetivos do programa, à ideologia da velhice e ao modelo do programa que se deseja instituir. 
Entretanto, como assegurado legalmente, o direito à educação deve ser garantido, e de qualidade. Segundo Libâneo (2004, p. 66):

Educação de qualidade é aquela que promove para todos o domínio de conhecimentos e o desenvolvimento de capacidades cognitivas, operativas e sociais necessários ao atendimento de necessidades individuais e sociais dos alunos, à inserção ao mundo do trabalho, à constituição da cidadania tendo em vista a construção e uma sociedade mais justa e igualitária. Em outras palavras, escola com qualidade social significa a inter-relação entre qualidade formal e política, é aquela baseada no conhecimento e na ampliação de capacidades cognitivas, operativas e sociais, com alto grau de inclusão.

Observa-se que existe um embate entre a EJA e a UNATI; esta última, de caráter extensionista, onde o primordial é a integração e participação do idoso, melhora da qualidade de vida, resgate da cidadania, elevação da autoestima e sua valorização como pessoa, com vistas à inclusão. Porém, o idoso para adentrar a UNATI precisa ser alfabetizado.

Universidades da Terceira Idade são programas de educação permanente de caráter universitário e multidisciplinar voltados a adultos maduros e idosos. Têm como pressuposto a noção de que a atividade promove a saúde, o bem-estar psicológico e social e a cidadania dessa clientela genericamente chamada de Terceira Idade. Os programas oferecem oportunidades para participação em atividades intelectuais, físicas, sociais, culturais, artísticas e de lazer. [...] Tirar os idosos do isolamento, propiciar-lhes saúde, energia e interesse pela vida e modificar sua imagem perante a sociedade foram desde o início, os objetivos da Universidade da Terceira Idade [...] (CACHIONI, 2008b, p. 207).

A UNATI destina-se ao público idoso aposentado que não necessita complementar sua renda com o trabalho, pois já possui uma escolaridade suficiente para atender aos anseios que a maturidade trouxe, buscando outras atividades culturais e de socialização. Já a EJA atende ao público que regressa aos estudos a fim de melhorar sua qualificação e capacitação para ser inserido no mercado. A aposentadoria que esses recebem não é suficiente para as suas necessidades básicas e é preciso uma complementação de renda. Portanto, o regresso aos estudos torna-se de suma importância.

O ensino formal da EJA busca proporcionar uma educação compensatória àqueles que não tiveram oportunidade de concluir seus estudos em tempo regular. No entanto, "deslocou-se a idéia de compensação para o campo da reparação e da equidade [...]" (SILVA; BARBOSA; UYTDENBROEK, 2008, p. 7). Porém, a EJA nem sempre atende às expectativas do idoso, pois trabalha da mesma maneira com os jovens e adultos (a partir de 
15 anos, falando de EJA - Ensino Fundamental I e II), visto que o contexto social de vivência desses se faz em épocas diferentes e as especificidades individuais dos mesmos não são consideradas.

A valorização das experiências vividas pelos idosos deve ser vivenciada na EJA, pois nessa modalidade de ensino a flexibilização do educador e a metodologia adotada permitem a contextualização dos conteúdos com a realidade desses indivíduos, ocasionando uma rede de interesse dos mesmos na continuidade dos estudos. Os idosos retornam aos bancos escolares na expectativa de que o ensino seja mediado da mesma forma que era em seu tempo regular, pois se cria uma convenção de que somente do modo tradicional se aprende. Assim,

\begin{abstract}
Muitos adolescentes, jovens, adultos e idosos ingressam na EJA trazem modelos internalizados durante suas vivências escolares ou por outras experiências. O modelo predominante é o da escola com características tradicionais, onde o educador exerce o papel de detentor do conhecimento, e o educando de receptor passivo deste conhecimento. Com base nesse modelo muitos depositam na escola a responsabilidade pela sua aprendizagem (PARANÁ, 2005, p. 34).
\end{abstract}

A educação para os idosos apresenta-se com o intuito de compartilhar saberes e conhecimentos, bem como aprendizagens significativas, não somente para o trabalho, mas também para assumir seus direitos, cumprir seus deveres, possuir autonomia, compreender o mundo e as tecnologias a sua volta e, por fim, envelhecer com dignidade, ou seja, obter e construir conhecimentos para a vida.

Em alguns casos, os idosos possuem dificuldades na visão e na audição, acarretando um prejuízo no seu aprendizado, pois não têm a mesma capacidade e disposição de um jovem. Dessa forma, suas dificuldades devem ser individualmente atendidas, apoiando-se, assim, na utilização de tecnologias que supram essas distorções/deficiências. Muitos ainda têm um processo mínimo de leitura e escrita sem conexão com a realidade e ficam na condição de analfabetos funcionais.

O computador é uma das ferramentas tecnológicas que pode ser utilizada como referencial, pois documentos e textos podem ser trabalhados nele ou impressos, atendendo ao tamanho de letra adequada aos idosos e conduzindo a novos métodos de alfabetização.

Percebe-se que a escolarização na EJA deve partir da aprendizagem, das experiências e do conhecimento construído ao longo dos anos pelos idosos. 
A educação prevista como direito é um dos itens básicos para se alçar a cidadania. Nela, questões que envolvam a fala e a escrita induzem ao levantamento de problemas e à busca de soluções, além de favorecer o aculturamento e a construção desmistificadora de uma sociedade mais humana e igualitária, que respeite as diferenças. No entanto, além da educação, o trabalho também é considerado um dos meios para se alcançar a dignidade e a cidadania.

Como a cidadania é exercício, é movimento, educar para a cidadania é estabelecer o desenvolvimento de um processo de aprendizado social na construção de novas formas de relação, contribuindo para a formação e constituição de cidadãos como sujeitos sociais ativos. O desafio se torna particularmente interessante quando enfrentado junto ao segmento idoso, onde é comum encontrar pessoas que viveram toda uma vida muitas vezes passada ao largo da possibilidade de fazer a reflexão sobre o significado da sua condição de cidadão. E como é possível começar a exercer a cidadania em qualquer etapa da vida, espaços que possibilitam a educação para a cidadania, como as universidades abertas à terceira idade, centros de convivência, grupos de reflexão, entre outros, tem levado os idosos a se perceberem e serem fortalecidos na sua condição de cidadãos, sujeito de direitos (BRUNO, 2003, p. 75).

Dessa forma, observa-se que os idosos possuem direitos e devem reivindicá-los, como prevê o Estatuto do Idoso e a Declaração dos Direitos Humanos; a velhice é uma fase de transformações do ser humano e a sociedade deve amparar, proteger e subsidiar a inclusão, garantindo uma melhor qualidade de vida dos mesmos.

Porém, para realmente romper com os mitos e preconceitos referentes à capacidade e aptidão, que conduzem aos constrangimentos e exclusões dos idosos, faz-se necessário conceder a ampliação do direito pleno da cidadania. Assim, situações de generalização indevida, que ocorrem permeadas pelas especificidades dos idosos, os colocam como ineficientes globais de suas condições físicas e psicológicas.

Com isso, a Lei no 8842/94, em seu Decreto nº 1948/96, nos fala sobre a Política Nacional do Idoso em seu Art. 11ํㅜ que estabelece: “Ao Ministério do Trabalho, por meio de seus órgãos, compete garantir mecanismos que impeçam a discriminação do idoso quanto à sua participação no mercado de trabalho" (BRASIL, 1996). 
O mercado de trabalho surge como um segmento que oportuniza o cumprimento da garantia dos direitos sociais, da participação e inserção social e política. Portanto, há uma contradição e dualidade entre o capitalismo e a legislação, pois enquanto um desvaloriza, o outro readmite; essa ordem de organização do Estado nos remete à imposição das classes dominantes, voltada ao capital internacional, que impõe:

\section{[...] imagens da velhice bem sucedida, saudável e ativa difundida por esses programas e políticas camuflam o envelhecimento do trabalhador e sua velhice doentia, dependente, pobre e desprotegida, negando a "problemática social" do envelhecimento, tratando, como de responsabilidade dos indivíduos, um problema que é social por meio de uma cultura autopreservacionista que pretensamente seria capaz de evitar os efeitos do envelhecimento (TEIXEIRA, 2008, p. 35).}

As políticas voltadas aos idosos não levam em consideração o objetivo central do envelhecimento. $O$ trabalho é considerado mais um meio de autoajuda e filantropia, reforçando mais as questões de privação e aumentando os problemas quanto à integração, inclusão, socialização e reinserção desse público na sociedade.

Nessa perspectiva, há um diferenciamento social voltado aos idosos trabalhadores que nos remete à sua pseudovalorização, atendendo somente as regras do capital. Com isso, deixam-se de lado as necessidades psicossociais, culturais e genético-biológicas, que geram um embate entre as leis e a lógica do capitalismo. As consequências ocasionadas se devem às condições precárias de trabalho, ao regime extensivo de horas e às práticas repetitivas, convencionadas para gerar lucro.

Outro aspecto volta-se ao crescimento demográfico desse público e, além disso, à aceleração da degradação física (funcional), orgânica e fisiológica, além da degradação social, voltada à exclusão, isolamento e desvalorização, fazendo desses indivíduos seres dependentes dos recursos públicos e assistenciais (TEIXEIRA, 2008, p. 76).

A reinserção dos idosos no mercado/mundo do trabalho é simplesmente um cumprimento de leis cotistas que estabelecem um trabalho formal.

O aumento da parcela da PEA ${ }^{6}$ constituída por aposentados pode estar refletindo por um lado a maior cobertura do benefício previdenciário e por outro, o aumento da longevidade conjugado com melhores condições de saúde que

6 PEA - População Economicamente Ativa. 
permitem que uma pessoa ao atingir os 60 anos possa, com facilidade, exercer uma atividade econômica. Além disso, a aposentadoria por tempo de serviço permite uma aposentadoria precoce. Por outro lado, a contratação de um idoso apresenta para o empregador algumas vantagens em termos de custos relativamente à contratação de um não idoso. Por exemplo, o empregador não precisa pagar vale transportes para o maior de 65 anos. O idoso, por exemplo, pode também, com mais facilidade, aceitar um emprego com baixas garantias trabalhistas, tais como contribuição para a Seguridade Social, se é aposentado (CAMARANO, 2001, p. 7).

Quando não há essa intervenção do trabalho formal, o mesmo se estabelece em trabalhos informais e voluntários. Onde não são valorizados os conhecimentos adquiridos por toda a vida desses sujeitos, a velhice é considerada uma 'doença' e não existe a prospecção do desenvolvimento de novas habilidades. "Como parte desse sistema destacam-se as caixas de pensão e aposentadoria, que assimilam a velhice dos operários à 'invalidez', isto é, à incapacidade para produzir; medidas essas que visam também reduzir custos da produção" (TEIXEIRA, 2008, p. 89).

Compreende-se, com isso, que nem sempre o trabalhador idoso realiza uma atividade com prazer, pois é visto que a competitividade e as regras capitalistas exercem mais poder sobre a legislação. Dessa forma, ainda imperam bases de acumulação, produtividade e seletividade destes sujeitos que não são adequados aos parâmetros exigidos pelo mercado do trabalho. Em alguns casos, o trabalho é tido como forma de subsistência, de maneira a complementar a renda do idoso, "nesse sentido, trabalhar para o idoso aposentado pode significar renda mais elevada, bem como autonomia física e mental e maior integração social"' (CAMARANO; KANSO; MELLO, 2011, p. 60).

Observa-se, ainda, que a maioria dos indivíduos incluídos no mercado de trabalho são homens que realizam atividades repetitivas e sem valorização, por serem de simples execução e manuseio, não exigindo um conhecimento mais amplo do processo. Já as mulheres participam de trabalhos voluntários, não remunerados, ou, ainda, trabalham com artesanato e atividades domésticas, que não resultam em uma renda fixa para essas senhoras.

\section{Considerações Finais}

Tendo em vista as inquietações iniciais deste artigo, volta-se ao campo de trabalho para se obter muitas das sínteses aqui expressas e afirmadas 
pelos diversos autores analisados. Nota-se e elucida-se paulatinamente o grande vazio e distanciamento das políticas públicas educacionais voltadas aos idosos e as leis de nosso país que não amparam a realidade desses.

Claramente tem-se como exemplo a Política Nacional do Idoso, que tem vários artigos vetados, como é o caso do artigo 21, citado anteriormente, que não possui outro artigo aditivo nem complementar para suprir o que foi retirado.

Julga-se necessário rendermos nossos esforços a debates nas academias, principalmente nos cursos de licenciatura, para que haja uma mobilização da sociedade civil em torno de questões relativas à EJA e aos idosos, nos aspectos de formação profissional, sendo esta continuada com metodologias e reflexões da prática, além de estudos na área da gerontologia e o respeito para com a sabedoria desses. Assim,

Nesse quadro de revisão institucional dos sistemas escolares, torna-se uma exigência buscar outros parâmetros para construir a história da EJA. Se a organização dos sistemas de educação formal está sendo revista e redefinida a partir dos avanços da consciência dos direitos, a educação dos jovens-adultos tem de ser avaliada na perspectiva desses avanços (ARROYO, 2005, p. 44).

Com essa pesquisa tem-se que os idosos deste determinado grupo estudado buscam sua inclusão e reinserção no mercado de trabalho a partir de sua alfabetização ou no término de sua escolaridade na EJA. Contudo, as reformulações curriculares ainda não se apresentam reais, apenas delineiam adequações improvisadas. Dessa forma, o profissional docente media seu plano de trabalho com base na sua intuição, pois o aporte teórico-metodológico e os cursos de formação contínua e continuada ainda não se elencam como critério real da educação de jovens, adultos e, principalmente, idosos.

O refletir sobre os profissionais que atuam nessa modalidade e a evasão escolar dessa é uma questão que se deve iniciar a partir da construção de políticas públicas educacionais, desde a implantação curricular nos cursos de licenciatura até a utilização de práticas e métodos pelos profissionais da EJA, haja visto que o desencontro literal das ferramentas educacionais com as políticas públicas pode ser novamente o elo gerador da evasão escolar.

Percebemos também que a EJA é indiscutivelmente uma educação possível. Ou melhor, imprescindível. E que o fato do atraso para ingresso na educação formal não é motivo para o não ingresso mesmo que tardiamente, uma vez que a educação é um processo continuado e atemporal (LOPES; SOUZA, 2011, p. 19). 
Em decorrência disso, a EJA, que tem como marca expressiva a oferta educacional em diversos bairros da cidade, a matrícula em tempos distintos e a admissão de indivíduos de diversas idades, torna-se a opção mais acertada para os idosos trabalhadores que necessitam concluir sua escolarização formal. No entanto, há adequações profissionais e curriculares pertinentes e necessárias para serem revistas. Ao Estado, sugere-se proporcionar cursos de formação, bem como o acompanhamento de uma equipe multidisciplinar na escola, para atendimento desse grupo e dos demais.

No artigo 22 do Estatuto do Idoso (2003, p. 17), temos que: "Nos currículos mínimos dos diversos níveis de ensino formal serão inseridos conteúdos voltados ao processo de envelhecimento, ao respeito e à valorização do idoso, de forma a eliminar o preconceito e a produzir conhecimentos sobre a matéria".

Esse artigo nos propõe uma reflexão acerca da existência e valorização dos idosos, em ouvi-los e atendermos às suas necessidades individuais, e promovermos, ainda, sua reinserção, se essa for compatível com sua saúde física e intelectual, mas, principalmente, se esse for seu desejo. É preciso levar em consideração que sua reincorporação ao meio social pode dar-se não somente através do trabalho, mas também de espaços que contribuam com seu bem-estar e melhoria de qualidade de vida.

“O envelhecimento não é somente um 'momento' na vida do indivíduo, mas um 'processo' extremamente complexo e pouco conhecido, com implicações tanto para quem o vivencia como para a sociedade que o suporta ou assiste a ele" (FRAIMAN, 1995, p. 19).

Com isso, vê-se que a sociedade subjuga os idosos como seres improdutivos e incapazes; porém, ressalta-se com esse artigo que os mitos e preconceitos devem ser desmistificados para a condução do crescimento cultural e intelectual de uma sociedade. Assim, para o pleno desenvolvimento da mesma, deve-se imperar o respeito para com todos. Nesse sentido, Cachioni (2008a, p. 92), propõe:

1 - Educação para os idosos: programas educacionais voltados a atender às necessidades da população idosa considerando as características desse grupo etário;

2 - Educação para a população em geral para a velhice e os idosos: programas educacionais que possibilitam à população mais jovem rever seus conceitos sobre a velhice e aos idosos rever o seu próprio processo de envelhecimento; 
Dessa forma, a UNATI é uma opção possível de educação para os idosos, pois proporciona um espaço socializador, interativo e exclusivo para esse grupo. Nesse entorno, encontram-se indivíduos com os mesmos interesses, necessidades, carências, etc., que são compartilhados e vivenciados através de práticas educativas voltadas a atender e preencher as lacunas que, por vezes, nesse momento da vida, encontram-se em aberto.

Contudo, para que essa educação social transforme-se em igualitária e contemple um número expressivo de indivíduos, sugere-se uma reestruturação, articulação e ampliação na divulgação, funcionamento e localização de espaços para o desenvolvimento dessa modalidade (UNATI). Há espaços escolares, associações de bairros, salões paroquiais, entre outros, que podem abrir-se para ofertar projetos de interesse comum aos idosos.

Outra proposta possível para a UNATI é o levantamento de questões para com os idosos, no que diz respeito aos seus interesses, anseios, dificuldades, etc., bem como uma abertura de atendimento no turno noturno e a inclusão de idosos da periferia como critério de funcionamento para essa modalidade.

Nesse entorno, o papel da UNATI, que se encontra restrito a um público alvo (indivíduos idosos pertencentes aos bairros centrais próximos ao local de seu funcionamento, e com disponibilidade de participação em horário comercial), poderá abrir-se ao compartilhamento e convivência para com os idosos trabalhadores, que ainda encontram-se excluídos desse direito social, demarcado pela estruturação burocrática e curricular dessa educação.

A Universidade deve prestar-se, além da abertura do espaço, para o funcionamento dessa educação, pois se indica que essa proporcione cursos de extensão docente, palestras, vínculos e estágios de seus acadêmicos de diversos cursos para o atendimento global do idoso, evitando, assim, situações de preconceito e exclusão, entre outras.

Enfim, reconhecer as especificidades e conhecimentos adquiridos ao longo da vida permite, aos idosos, valorização, respeito e reconhecimento de suas capacidades, e a educação (EJA) é uma das esferas que pode auxiliar para que se possa desmistificar a relação do idoso com o mercado de trabalho, desde que seu atendimento ultrapasse os limites curriculares. 
abstract

This article describes the profile of the elderly who seek on the Young and Adults Education (EJA) a way of reinsertion on the labor market. The aim is to contextualize the support of the Laws, Decrees and Statutes for these seniors, prioritizing their acquired rights and reducing the conflicts built by the capitalist system that does not meet their specifications and desires. Therefore, this article shows the distance of the educational public polices to the treatment of this people. The main objective is to discuss about the consequences and ways of how the society provides education and employment for the elderly. It's also notable the importance of the use of new technologies by these elderly to interact with other generations and, still, the gerontological education is interlined as a more appropriate way to meet the aspirations and needs of this portion of the population. From all these aspects, it's intended to demonstrate that the elderly is an active and participating citizen, which has the same importance as the other members of society. The research methodology draws upon the union of the case study of ethnographic kind with the survey research, of qualitative imprint, in an exploratory approach. The text of this article is extremely relevant mainly to the EJA education teachers and to other educators, since they have the need to expand their formation in this area of knowledge.

keywords

Elderly. Adult Education. Labor Market.

referências

ANDRÉ, M. E. D. A. Etnografia da prática escolar. São Paulo: Papirus, 2008.

ARROYO, Miguel G. Educação de Jovens-Adultos: um campo de direitos e responsabilidade pública. In: SOARES, Leoncio; GIOVANEITI, Maria Amélia; GOMES, Nilma L. (Orgs). Diálogos na educação de jovens e adultos. Belo Horizonte: Autêntica, 2005. p. $19-50$

BRASIL. Ministério do Planejamento, Orçamento e Gestão. Instituto Brasileiro de Geografia e Estatística (IBGE). Síntese de Indicadores Sociais: Uma análise das condições de vida da população brasileira. Estudos e Pesquisas. Rio de Janeiro, ISSN 1516-3296, n. 27, 2010. 
Decreto no 1948/96. Política Nacional do Idoso. Brasília, 1996. Disponível em: <http://www. planalto.gov.br/ccivil_03/decreto/d1948.htm>. Acesso em: 5 jul. 2011.

BRUNO, Marta Regina P. Cidadania não tem idade. Serviço Social \& Sociedade - Velhice e Envelhecimento, São Paulo: Cortez, ano 24, n. 75, p. 74-83, set. 2003.

CACHIONI, Meire. Gerontologia educacional/educação gerontológica. In: NERI, Anita L. (Coord.). Palavras-chave em gerontologia. Campinas: Alínea, 2008a. p. 92-95.

Universidade da Terceira Idade. In: NERI, Anita L. (Coord.). Palavras-chave em Gerontologia. Campinas: Alínea, 2008b. p. 207-210.

CAMARANO, Ana Amélia; KANSO, Solange; MELLO, Juliana L. Como vive o idoso brasileiro? Rio de Janeiro: IPEA, 2004. Disponível em: <http://www.nescon.medicina. ufmg.br/biblioteca/imagem/0191. pdf>. Acesso em: 14 out. 2011.

CAMARANO, Ana Amélia. O idoso brasileiro no mercado de trabalho. Rio de Janeiro: IPEA, 2001. Disponível em: <http://www.ipea.gov.br/portal/images/stories/PDFs/TDs/ td_0830.pdf>. Acesso em: 25 set. 2013.

CHIZZOTTI, Antonio. Pesquisa qualitativa em ciências humanas e sociais. Petrópolis: Vozes, 2006.

FRAIMAN, Ana P. Coisas da Idade. São Paulo: Editora Gente, 1995.

GADOTTI, Moacir. A questão da educação formal/não formal. Suíça, 2005. Disponível em: $<$ http://uww.virtual.ufc.br/solar/aula_link/lipt/A_a_H/estrutura_politica_gestao_organizacional/ aula_01/imagens/01/Educacao_Formal_Nao_Formal_2005.pdfs. Acesso em: 25 set. 2013.

LIBÂNEO, José Carlos. A organização e gestão da escola: teoria e prática. Goiânia: Alternativa, 2004.

LOPES, Selva P.; SOUZA, Luzia S. EJA: uma educação possível ou mera utopia? Disponível em: <http://www.cereja.org.br/pdf/revista_v/Revista_SelvaPLopes.pdf>. Acesso em: 30 jun. 2011.

MINAYO, Maria Cecília de S. Ciência, técnica e arte: o desafio da Pesquisa Social. In: p. $9-30$ (Org.) Pesquisa social: teoria, método e criatividade. Petrópolis: Vozes, 2001. 1994.

O desafio do conhecimento. São Paulo/Rio de Janeiro: HUCITEC-ABRASCO,

NERI, Anita L. (Coord.). Palavras-chave em gerontologia. Campinas: Editora Alínea, 2008.

OsoRIO, Agustin R. Educação Permanente e Educação de Adultos. Lisboa: Instituto Piaget, 2003.

PARANÁ. Secretaria de Estado da Educação. Diretrizes cumiculares para jovens e adultos - Versão preliminar. Curitiba, 2005.

PATROCINIO, Wanda P. Trabalhador idoso. In: NERI, Anita L. (Coord.) Palavras-chave em gerontologia. Campinas: Editora Alínea, 2008. p. 204-207.

SILVA, Fernanda Maria; BARBOSA, Marina A.; UYTDENBROEK, Xavier. A função social da escola na Educação de Jovens e Adultos - Escola: pra quê te querem? Recife: UFPE, 2008. Disponível em: <http://mww.ufpe.br/ce/images/Graduacao_pedagogia/ pdf/2008.1/pdf>. Acesso em: 20 out. 2011.

SOUZA, João Francisco de. Educação e sociedade na perspectiva Freireana. Revista Educação, Porto Alegre, ano XXV, n. 46, p. 67-89, mar. 2002. 
Recebido: 13/07/2011

$1^{a}$ Revisão: 10/01/2012

2a Revisão: 24/09/2012

Aceite Final: 28/09/2012
TEIXEIRA, Solange Maria. Envelhecimento e Trabalho no tempo do capital: Implicações para a proteção social no Brasil. São Paulo: Cortez, 2008.

VARGAS, Isabel C. S. Educação x Terceira Idade. 2010. Disponível em: <http://unw. webartigos.com/articles/32199/1/EDUCACAO-X-TERCEIRA-IDADE/pagina1.html>. Acesso em: 30 jun. 2011. 